Agricultural Policy Research in Africa

\title{
ROLE OF RESILIENCE FACTORS IN MITIGATING THE NEGATIVE EFFECTS OF CONFLICT ON LAND EXPANSION
}

Adesoji Adelaja, Justin George, Thomas Jayne, Milu Muyanga, Titus Awokuse, Lenis Saweda O. Liverpool-Tasie and Adebayo B. Aromolaran 


\section{CONTENTS}

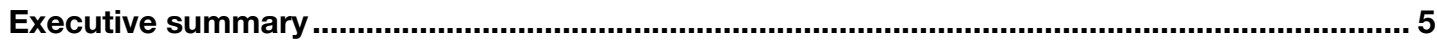

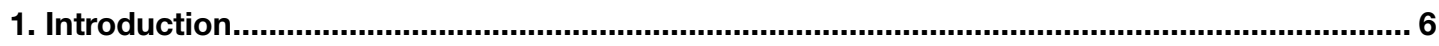

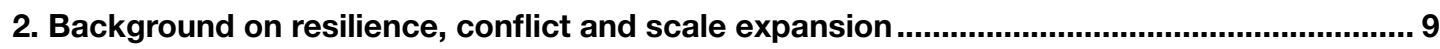

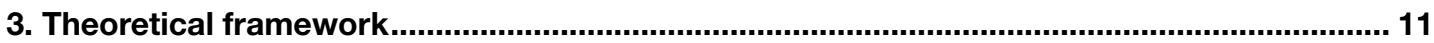

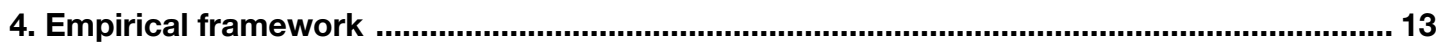

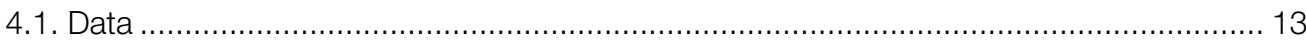

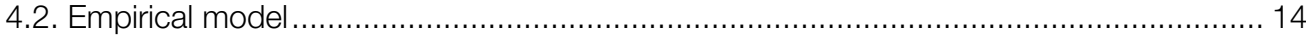

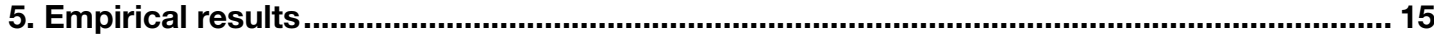

5.1. Role of resilience factors in mitigating the impacts of conflict on the transition ............... 15

5.2. Differential effects of resilience factors: Kaduna versus Ogun states ............................. 17

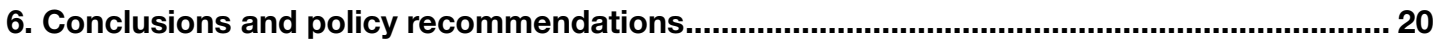

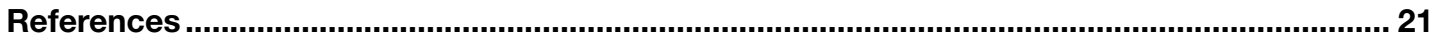

Tables

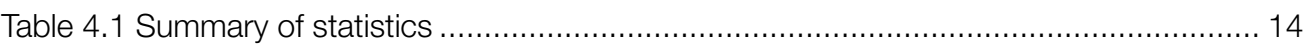

Table 5.1 Role of resilience factors in mitigating the negative impacts of conflict on the transition to larger scales (asset value and net off-farm income as resilience factors - pooled data) ..... 15 Table 5.2 Role of resilience factors in mitigating the negative impacts of conflict on the transition to larger scales (household income and education as resilience factors - pooled data) ......... 16 Table 5.3 Role of resilience factors in mitigating the negative impacts of conflict on the transition to larger scales (asset value and net off-farm income as resilience factors). 18

Table 5.4 Role of resilience in mitigating the negative impacts of conflict on the transition to larger scales (household income and education as resilience factors) 


\section{ACKNOWLEDGEMENTS}

Funding for this research is provided by Agricultural Policy Research in Africa (APRA), a five-year research programme consortium. Running from 2016-2021, this programme is funded by the Bill and Melinda Gates Foundation, based at the Institute of Development Studies (IDS), UK (www.ids.ac.uk). The goal is to build on more than a decade of research and policy engagement work by the Future Agricultures Consortium. We are grateful for this generous support and we thank the paper's reviewers for their valuable inputs.

Adesoji Adelaja is the John A. Hannah Distinguished Professor in Land Policy in the Department of Agricultural, Food and Resource Economics (AFRE) at the College of Agriculture and Natural Resources, Michigan State University (MSU). Justin George is an assistant professor at AFRE. Thomas Jayne is a MSU foundation professor in AFRE. Milu Muyanga is an assistant professor at AFRE. Titus Awokuse is professor and Chair of AFRE. Lenis Saweda O. Liverpool-Tasie is an associate professor at AFRE. Adebayo Aromolaran is a professor and Dean of the Faculty of Agriculture, at Adekunle Ajasin University, Akungba-Akoko.

This working paper is funded with UK aid from the UK government (Foreign, Commonwealth \& Development Office - FCDO, formerly DFID). The opinions are the authors and do not necessarily reflect the views or policies of IDS or the UK government. 


\section{ACRONYMS}

APRA

ACLED

BH

IDP

LGA

LCF

MSF

PRIO

RIMA

SHF

SME

SPEI

SSA
Agricultural Policy Research in Africa

Armed Conflict Location \& Event Data Project

Boko Haram

internally displaced persons

local government area

large commercial farm

medium-scale farm

Peace Research Institute of Oslo

Resilience Index Measurement Analysis

smallholder farm

small and medium-sized enterprise

Standardized Precipitation-Evapotranspiration Index

sub-Saharan Africa 


\section{EXECUTIVE SUMMMARY}

Facilitating the expansion of the land bases of smallholder farmers who have the capacity to do so is an important issue in agricultural transformation, poverty alleviation and food security in Africa. However, shocks and stresses from natural disasters, climate change, economic volatility, armed conflicts and political instability could hinder the expansion efforts by smallholder farms (SHFs). The application of the resilience concept as a mitigator of the impacts of such shocks on land expansion by farmers is an important developmental challenge.

In this paper, we hypothesise that conflicts constrain the ability to do so, but that the resilience capacity of SHFs mitigate the adverse effects of conflict shocks. In the absence of adequate data to construct a composite variable, we investigate the roles of commonly cited component resilience factors in mitigating the effects of conflict shocks on the abilities of farmers to expand their land holdings. Specifically, we examine how assets, off-farm income, access to social safety nets, and education level of the household lead contribute to household-level resilience to armed conflicts. We apply a model with interaction terms between conflict and resilience factors to data on a sample of farmers from Ogun and Kaduna states of Nigeria, two states not directly in a major conflict zone.

Our results confirm the detrimental effects of conflict on the likelihood that a SHF household will expand its land base to become a medium-scale farm (MSF) household and that resilience factors such as assets, education, off-farm income and access to social safety nets help mitigate these detrimental effects. We also find that the mitigating roles of resilience factors are more pronounced in Kaduna State than in Ogun State. This is expected, considering the greater exposure of Kaduna State to more debilitating forms of conflict.

The resilience building tools implied by this study as being relevant are improved education, improved access to safety nets and improved assets. Improved safety nets can be achieved both through government programmes to help farmers and better extension education programmes. While large asset holdings can be viewed by some as a distraction in volatile conflict settings, its beneficial effect as a resilience factor renders it desirable in areas affected by conflict.

\section{Keywords}

Resilience factors, conflicts, land expansion, agriculture, climate-related shocks, natural disasters 


\section{INTRODUCTION}

Sub-Saharan Africa (SSA) has been experiencing increased urbanisation, rising metropolitan population densities and a growing middle class (Hazell 2018). These trends, which will likely continue well into the future, are further driving growing demand for food and agricultural products, especially value-added products, and a broader variety of such products (Jayne, Chamberlin and Headey 2014; Masters et al. 2013). The farms which are needed to help meet these new demands are mostly in rural areas, and most of them are SHFs (Lowder, Skoet and Raney 2016). Therefore, opportunities exist to transform agriculture and reduce poverty by better connecting SHFs to urban market opportunities.

More specifically, SHFs face two major alternative options: (1) diversify their products to try and match urban demands for value added agricultural products such as vegetables and meats; better connect to MSFs or large commercial farms (LCFs), many of which are already well connected to urban market opportunities, and connect better with the growing number of small and medium-sized enterprises (SMEs) across the food value chain; (2) scale up their own operations to become MSFs or LCFs. Those SHFs with the potential or ability to scale-up must inevitably expand their land base. Given their subsistence nature, their transition to larger scales is crucial in improving household income, reducing food insecurity, and eliminating poverty in rural areas.

SHFs with scale-up aspirations or capabilities face several barriers to scale expansion, including the lack of access to capital, which is often a result of the lack of an effective land tenure or titling system; limited access to technology; low productivity and lack of access to markets (Barrett 2008), which translate into low income; and limited land availability due to population pressures (Masters et al. 2013). The lack of an effective land tenure system is foundational to many of these barriers. Conflicts may well be another barrier to scale expansion. Today, over 2 billion of the world's population live in countries affected by conflict, violence and fragility (FAO et al. 2017; Holleman et al. 2017). In recent years, SSA has significantly experienced growing incidences of armed conflict (ACLED 2019; Raleigh et al. 2010). Given their debilitating effects, the agricultural impacts of conflicts in these affected areas have drawn the attention of researchers and policy makers.

Specifically, armed conflicts have been shown to adversely affect agricultural production, labour utilisation, optimal land use and other agricultural outcomes in active conflict zones (Adelaja and George 2019a; 2019b). Armed conflicts have also been shown to retard the ability of SHFs to scale up their operations and become larger farms, even in areas beyond conflict zones that are experiencing the spill over effects of conflict (George, Adelaja and Awokuse 2020).These spill over effects may arise from human displacement, migration by farmers, disrupted product and input markets, weakened food supply chains and reduced domestic trade (Adelaja and George 2019a; 2019b). Evidence on the impact of conflict on farmers' ability to expand their land base and the relative roles of various factors in mitigating such impacts are critical to policy decisions concerning SHFs scale expansion. This is the case not only in conflict zones, but also in non-conflict zones.

In simple terms, resilience is the ability to withstand an extraneous shock and return-back to normal. More broadly, Barrett and Constas (2014) define it as the capacity over time of a person, household or any other aggregate unit to avoid poverty in the wake of a myriad of shocks. In the context of a conflict shock, given the disruptive nature of these events, resilience can be defined as the ability to return-back to preshock levels or to a new (possible or preferred) normal after an armed conflict incident has abated. If conflicts retard scale expansion, then resilience factors can be expected to improve bounce-back ability.

The concept of resilience is gaining major prominence among international development and relief agencies (Carr 2019; Cissé and Barrett 2018). For example, many developed countries and their donor agencies now place resilience building at the centre of their programmes (Cissé and Barrett 2018)' as they search for more sustainable and targeted development strategies in areas affected by shocks. Some 
developing countries are already concerned about how the concept of resilience might be relevant to their efforts to mitigate the effects of shocks and recover from their debilitating effects (d'Errico and Di Giuseppe 2018). These interests are largely driven by growing concerns about the roles of shocks and stresses from natural disasters, climate change, economic volatility, armed conflicts and political instability in overturning previous development successes (George, Adelaja and Weatherspoon 2020). It could be postulated that building resilience to shocks and stresses can reduce the high human and economic costs of repeated humanitarian efforts and associated political and public pressures.

While the resilience concept has gained significant interest, several issues make its practical application difficult in the development context. First, the choice of the right resilience measure is highly dependent on the type of shock or stressor investigated. Second, given its dynamic nature, sufficient time-variant data are typically lacking to allow its measurement, especially in developing countries where major data gaps exist. Researchers and policy makers therefore struggle to develop methods to empirically implement the resilience concept so as to guide policy and programme design, measure progress and evaluate appropriate interventions (Cissé and Barrett 2018). The application of the resilience concept as a mitigator in the examination of the impact of conflict on land expansion by farmers has not been pursued in the literature.

Resilience frameworks created to model the impacts of shocks, in general, may not translate well to conflictrelated shocks as they significantly differ from other shocks in their resilience implications. First, as armed conflicts are often endogenous to existing levels of resilience and the factors that determine them, the lack of resilience itself could be a contributing factor to conflict. This aspect is notably different from climaterelated shocks and natural disasters, which are mostly exogenous in nature. Second, as armed conflicts often lead to massive population displacements, resilience factor may well affect people's choices to stay or to flee and thereby patterns of migration for internally displaced persons (IDPs). For example, anecdotal evidence from Nigeria suggests that many of the IDPs who fled from the Boko Haram $(\mathrm{BH})$ conflict zone resumed their previous activities in host communities, rather than become wards of the state or humanitarian agencies in IDP camps (Adelaja and George 2019b). Third, unlike climate-related shocks, conflicts cause major disruptions in social and political support systems which are fundamental to resilience. Traditional leaders, chiefs and elders are often separated from their constituents, thereby reducing their authority (van der Haar and van Leeuwen 2019). These distinctive features call for more focused analyses of the roles of resilience-related factors in mitigating the negative impacts of conflict shocks.

The elusiveness of the concept of resilience, due to measurement and data problems, limits the ability to investigate its role in the scale-up of farmland holdings. However, in the absence of sufficient time-series data to measure resilience as a variable, resilience indicators can be used instead in empirical investigation of the role of resilience in mitigating the effects of conflict. Fortunately, the literature on resilience has identified several pillars of resilience, which are useful in conducting such analysis. For example, d'Errico and Di Giuseppe (2018) identify the following broad categories of resilience pillars: (1) income levels, sources and food access, (2) assets holdings, (3) access to basic services, (4) the existence of social safety nets, and (5) adaptive capacity. These pillars help mitigate the effects of shock by providing coping strategies such as consumption smoothening, asset selling and new livelihood options. If it is economically optimal for a SHF household to expand its land holdings, we expect that these pillars of resilience will mitigate the effects of a shock on the ability to do so. As demonstrated below, the availability of retrospective data, along with data on the indicators of resilience, can be used to measure the roles of these factors as proxies for a resilience variable or index. Evidence on the role of resilience in mitigating the impacts of conflict on agriculture is sparse. The same applies to its role in mitigating the adverse effects of conflict on the transition from SHFs to larger scales.

Using Nigeria as a case study, we investigate the role of resilience building factors in mitigating the adverse effects of conflicts on the ability of SHFs to scale-up. Specifically, we examine how assets, off-farm income, access to social safety nets, and education level of the household lead contribute to household-level resilience to armed conflicts. For this purpose, we utilise the recently completed Agricultural Policy Research in Africa (APRA) survey database for Nigeria, which administered focused questions to farmers who made the transition from small-scale to larger-scale farming in Kaduna State (in the north-west of Nigeria) and Ogun State (in the south-west of Nigeria). We exploit the geocoded nature of the APRA survey by spatially joining it with the Armed Conflict Location \& Event Data Project (ACLED). The latter allowed us to more accurately measure the exposure of each farm household to conflict incidence. Our empirical model involves the use of cross variables between resilience factors and 
conflict variables in order to tease out the direct effects of conflict and the indirect mitigating effects through resilience factors. Our empirical analysis also includes various control factors such as climate, historical land tenure and farm management factors. Our results help quantify the relative contribution of various resilience building factors in enabling households to expand the scales of their operations.

Although the bulk of the $\mathrm{BH}$ attacks took place in the north-east of Nigeria, Kaduna State experienced several direct attacks from BH (ACLED 2019; Raleigh et al. 2010) and other spill over effects of BH's direct attacks through IDPs, input and product markets, as well as inter-state trade. Kaduna State farmers also faced instances of Fulani herdsmen conflicts resulting from transhumance. Therefore, data from Kaduna allows for a deeper dive into the possible effects of conflict in an area that is not in an active conflict or war zone like the north-east and where the effects of $\mathrm{BH}$ attacks are probably more temporary. In Ogun State's case, BH's presence was not significant, but other minor and more sporadic conflicts such as riots and demonstrations occurred. Nigeria is also an ideal example of countries where conflicts may have had detrimental impacts on SHFs' ability to expand their land-bases. The ongoing $\mathrm{BH}$ insurgency has negatively impacted the agricultural land in use via farmer casualty, disability and injury, reduction of agricultural activities, abandonment of farm fields, takeover of farm control and lack of required inputs for returning farmers (Adelaja and George 2019a). In addition, many places have also experienced increased pastoral violence, as Fulani herdsmen, who historically only grazed their animals seasonally in the Middle Belt and southern Nigeria, are increasingly grazing at these destinations and for longer periods of time.

Our approach differs from various other papers in the following ways. First, to the best of our knowledge, this is the first study which explains land ownership transition outcome within a resilience framework. Second, we focus on armed conflict as a shock/stressor, in comparison with most of the previous studies which focus predominately on climate-related shocks. Third, unlike most studies, we focus on two areas that are not directly in an immediate major conflict zone but may be affected by conflict, albeit milder forms. Finally, we directly explore the implications of resilience factors for the ability of SHFs to scale-up, thereby making it possible to explain how these factors feature in policies to encourage the transition of SHFs to larger scales.

The rest of this paper is organised as follows. In Section 2, we discuss the concept of resilience and its role in achieving development targets. We also review the literature on the role of resilience related factors in moderating the relationship between conflict and agriculture. In Section 3, we present a simple conceptual model to explain the role of resilience in mitigating the negative impacts of conflict shocks on farmer's decisions to expand their operations. In Section 4, we describe Kaduna and Ogun states, our research venues; the nature of the data;ii our various control factors; and our empirical framework. In Section 5, we present and explain our main empirical results. Conclusions and policy recommendations appear in Section 6. 
The definition and measurement of resilience in a development context has evolved significantly in the last few years. Despite a delayed adaptation of the concept by the development scholars, vis-à-vis their counterparts in ecology, engineering, psychology and epidemiology (Gunderson 2000; Holling 1973), its rise to the centre of development literature was driven by the significant increase of armed conflicts, climate changes and various other shocks and stressors over the last few years. Alinovi and Romano (2010) probably made the first notable attempt to define and measure resilience in an area related to agriculture, but their primary outcome variable of interest was food security. Their conceptualisation of resilience as a latent variable associated with household capacity building potential did not explicitly involve any shock variables. Furthermore, Frankenberger and Smith (2015) and Smith and Frankenberger (2018) provided welfare-based measures of resilience, with the latter specifically focusing on vulnerable communities with high levels of exposure to shocks and stresses.

A comprehensive measure of resilience was developed by FAO (2016) when their Resilience Index Measurement Analysis (RIMA) yielded a composite resilience index, namely Resilience Capacity Index (RCl). Using Uganda as a case study, they developed this index based on various observable measures, classified under five main pillars: incomes, access to basic services, assets, social safety nets and adaptive capacity, all of which translate into stability. The index was calculated using a Multiple Indicators Multiple Cause model. However, FAO's resilience measurement methodology, just like other measures, is static in approach. More recently, following the work of Barrett and Constas (2014), Cissé and Barrett (2018) recognised that the concept of resilience may be better conceptualised as a dynamic concept. Using a panel data structure, Cissé and Barrett (2018) therefore, developed a dynamic moments-based approach in estimating resilience. Finally, d'Errico and Di Giuseppe (2018) combined both these approaches and used FAO's RIMA approach in a dynamic setting while allowing comparisons between resilience building capacity of households in Ethiopia and Uganda.
Based on previous literature, our preferred definition of resilience aligns more closely with the definition by the Technical Working Group on Resilience Measurement set up by FAO, the International Food Policy Research Institute, and World Food Programme (Choularton et al. 2015). According to them, resilience is "the capacity that ensures adverse stressors and shocks do not have long lasting adverse development consequences". This definition suggests that the concept of resilience is based on the following premises: (1) that an "agency" (household/individual or community), whose capacity to absorb, adapt and transform livelihoods is at the centre of measuring resilience; (2) that a pre-defined outcome or set of outcomes measuring the wellbeing of an individual, household or community/country, is required; (3) that exposure to specific shocks and stressors is a requirement; and (4) that there is a trajectory or path of the outcome variable over time. Next, we discuss each of the above four elements in detail and how they manifest themselves in the context of our study.

In our analysis, we focus on households as the agencies which are resilient when faced with shocks and stressors. This focus is important as household units are central to effectively responding to external stimuli during conflicts and post-crisis interventions are often directed at more disaggregated levels (Toole, Klocker and Head 2016). Moreover, many of the assets, capacities and functions critical in responding to shocks and stressors are guided by householdlevel dynamics (Barrett, Reardon, and Webb 2001). Assessments of household resilience also complement national, community and individual level assessments since the associated capacities and vulnerabilities may end up being quite different to those measured at a macro-scale (Toole, Klocker and Head 2016). Most importantly, household-level assessments often serve as an intermediate step between individual-level decisions and their possible interactions with broader social norms, behaviour and institutional structures critical in tackling crisis situations (Jones and Tanner 2017; Adger et al. 2009; Adger 2000).

Second, our predefined outcome variable is the curtailed ability of a SHF household to transition to 
larger scales when exposed to specific shocks and stressors. In our study, the term "smallholder farmers" refers to farmers operating small land parcels. iii About 41 million of the total of 51 million farms in Africa (80 per cent) are SHFs operating less than 2ha (Lowder, Skoet and Raney 2016). iv Given their dominance in the agriculture landscape, transformation of SHFs is critical for a reduction in poverty and food insecurity in Africa. Improving the productivity of SHFs and better connecting them to the growing number of larger producers and SMEs along the value chain is essential in improving their incomes and employment capacity. The number of SHFs is also increasing in many countries (Headey 2016). However, over the recent years, very few farms have successfully completed the transition from SHFs to larger scales (Jayne et al. 2019). These numbers coincide with a significant increase in various shocks and stressors in the regions, especially in the form of social unrest and climate related factors. Understanding how SHFs fare when exposed to shocks and which factors help these farms to cushion the negative impacts of shocks is important for post conflict reconstruction and redevelopment efforts. By measuring the outcome variable as to whether the transition was made in the last five years, we also capture the long-lasting effects of an exposure to conflict.

Third, the shocks we primarily identify in this study are from armed conflicts, a major shock impacting on development outcomes today. In the last decade, the spread and intensity of domestic armed conflicts have significantly increased, especially in developing countries. For example, in 2016, out of a total of 815 million undernourished people, 60 per cent lived in countries struggling with conflict, violence and fragility (FAO et al. 2017). Furthermore, the prevalence of undernourishment in the 46 low and middle-income countries affected by conflict is, on average, between 1.4 and 4.4 per cent points higher than all other countries in the same income categories (Holleman et al. 2017). According to the (BIFAD 2019), "today, addressing food insecurity means operating amidst conflict and fragility. Last year, every country in a protracted food crisis was also engaged in violent conflict". Finally, the trajectory or path is the delayed acquisition of land. Resilient households can bounce back quicker because they have the assets and other capabilities to do so. Empirical evidence from affected countries also suggests that armed conflicts adversely impact on agricultural production (Adelaja and George 2019a), the outputs of specific crops (Adelaja and George 2019a), land use choices (Adelaja and George 2019b), cropping practices (Bozzoli and Brück 2009), food security (George, Adelaja and Weatherspoon
2020), the nutritional status of children (Minoiu and Shemyakina 2014; Akresh, Lucchetti and Thirumurthy 2012; Bundervoet, Verwimp and Akresh 2009), calorie intake (D'Souza and Jolliffe 2013), labour market outcomes (Kondylis 2010) and farmers' investments choices (Arias, Ibáñez and Zambrano 2019).

Like other shocks, certain individuals/households have better resilience mechanisms to withstand the negative impacts of these conflict-related shocks. The factors contributing to resilience building include social capital, human capital, exposure to information, asset holdings, livelihood diversity, safety nets, access to markets and services, women's empowerment, governance, and psycho-social capabilities such as aspirations and confidence to adapt (Aall and Crocker 2019; Massad et al. 2018; Breisinger et al. 2014; Hall et al. 2014). Although some of these factors are also found to contribute to resilience to other shocks (Frankenberger and Smith 2015) and improve resilience in post-conflict settings, there exists very little empirical evidence of their roles in the context of an ongoing conflict. Based on previous literature on resilience, we hypothesise that resilience factors used in our empirical analysis - assets, off-farm income, access to social safety nets, and education level of the household - mitigate the impacts of armed conflicts on SHF's ability to transition to larger scales.

In comparison with other shocks, the relative contribution of various factors to resilience development in conflicts can be significantly different. For instance, the amount of physical assets is considered to be a major contributor to resilience (Cissé and Barrett 2018). However, in severe conflicts, physical assets could prove to be a burden to many households seeking to relocate to safer areas, as liquidating assets is harder in conflict zones due to low market demand for such assets (Pivovarova and Swee 2015). In addition, different types of conflicts can also have different implications for the resilience of affected people. For instance, territorial terrorism, where non-state actors seek to create a parallel state and control territories, will differ in resilience implications from pastoral violence, which is largely seasonal and non-territorial in nature.

Finally, any effective measurement of resilience should capture the long-term trajectory of the outcome variable and how shocks impact these trajectories. This means that resilience, in its core, is a dynamic concept, not a static one. However, in this study, due to data limitations, we focus on a single time period and the various resilience related factors which help mitigate the negative impacts of armed conflicts on the transition from SHFs to larger scales. However, given that the APRA study is designed in a panel framework, further rollouts of additional waves will enable us to carry out a dynamic analysis in the future. 
Relying on previous studies that have documented the effects of conflict on agriculture (see Adelaja and George 2019a; 2019b), we present a simple framework for evaluating the roles of resilience factors in mitigating the effects of conflict on land expansion decisions. We define $A_{t}$ as the amount of land actively farmed by a farm household in time period $t$ and note that $A_{t}$ is the actual demand for land in production. Following Adelaja and George (2019b),

$A_{t}=A\left(a_{t}, w_{t}, c_{t}, p_{t}, Z, \epsilon_{t}\right)$,

where $a_{t}$ is the rental rate for land in time period $t, w_{t}$ is the wage rate for labour in time period $t, c_{t}$ is the cost per unit for non-labour inputs in time period $t, p_{t}$ is a vector of product prices in time period $t, Z$ is a vector of various fixed production-related factors and household characteristics influencing land demand and $\epsilon_{t}$ is an independently and identically distributed vector of random variables representing conflict-related shocks in time period $t$.

Further, we define $\bar{A}$ as the amount of family owned land and $A_{t t}$ as the amount of land idled. ${ }^{v}$ Therefore,

$A_{t}=\bar{A}-A_{\text {It }}$.

From Equation 2, when $A_{t}=\bar{A}$, then $A_{t t}=0$. This means that no land is idled. However, when $A_{t}>\bar{A}$, then $A_{t t}$ $<0$. This is when the farm household requires more land than it owns. In situations where $A_{1 / t}<0$, we use the notation $A_{E t}>0$ to reflect excess demand for land in production than what the farm household owns. In Equation 2, we make the simplifying assumption that no land is rented in or out and none is acquired or given away for free. In the context of active conflicts, this assumption is likely to hold true as persistent violence could lead to inactive land rental markets (Adelaja and George 2019b). Since $\bar{A}$ is purely fixed in the short term, $A_{/ t}$ can be represented as:

$A_{I t}=A\left(a_{t}, w_{t}, c_{t}, p_{t}, Z, \epsilon_{t}\right)$.

Since excess demand for land $\left(A_{E t}\right)$ exist only when $A_{t t}$ $<0$, a similar expression exists for $A_{E t}$ as in Equation 3 . Thus, $A_{E t}$ can be represented as:

$A_{E t}=A^{\prime}\left(a_{t}, w_{t}, c_{t}, p_{t}, Z, \epsilon_{t}\right)$.
Excess demand for land (Equation 4) is different from the decision to actualise excess land demand by $A_{E t}=\beta A^{\prime}\left(a_{t}, w_{t}, c_{t}, p_{t}, Z, \epsilon_{t}\right)$,

where ${ }^{*} A_{E t}$ is the decision to buy more land and $\beta$ is an actualisation parameter which is a function of factors that determine whether or not the household can actually execute its added demand for land. Note that $\beta$ may depend on several factors, including the affordability of land $(F)$ and the availability of land for sale in the area of the farm $(V)$. That is,

$\beta=\beta(F, V)$

The affordability factors include such things as household assets and off-farm income.

It is assumed that land is readily available, especially in an area affected by conflict, so that $\partial \beta / \partial V=0$. For instance, in ISIS-controlled Iraqi and Syrian zones, abandoned farm land was readily available, which was then used by the terrorists for agricultural purposes (Eklund et al. 2017; Jaafar and Woertz 2016). In addition, we assume that the greater the affordability of the farm household to expand the land base, the greater the probability of such expansion, therefore, $\partial \beta / \partial F>0$. Now, we represent $\beta$ as a variable which ranges from 0 to 1. $\beta=0$ denotes zero likelihood of actualisation which is when the farm household neither has the ability or capacity to scale up its land holding. $\beta=1$ denotes full ability to actualise the needed farm expansion.

From Equation 5, the effect of a conflict shock variable on the likelihood of scaling-up, as demonstrated in the example of non-labour input costs; this can be obtained by taking the derivative of ${ }^{*} A_{E t}$ with respect to the conflict shocks variable. That is,

$\frac{\partial * A_{E t}}{\partial \epsilon}=\frac{\partial * A_{E t}}{\partial c_{t}} \cdot \frac{\partial c_{t}}{\partial \epsilon}+\frac{\partial * A_{E t}}{\partial \epsilon}$.

From Equation 7, a conflict shock directly affects the ability to expand the land base, but also affects it indirectly through its impact on non-labour input costs, represented by $c_{t}$. The first term on the right of Equation 7 is the change in the probability to scale up through $c_{t^{*}}$. This is an indirect effect. The second term 
in Equation 7 is the direct effect of conflict shock, which we expect to be negative. The overall effect on the decision of the farm household to scale-up and buy more land depends on the direction and relative magnitudes of both terms.

To explore the role of resilience, we represent the measure of resilience as $R$. In the absence of a measure of resilience, we assume that it can be represented by specific resilience factors $\left(R_{m}\right)$, which include indicators of assets. We also assume that each $R_{m}$ ranges from 0.01 to 0.99. For all $R_{m} s, R_{m}=0.99$ (or $1-R_{m}=0.01$ ) represents almost absolute resilience where the farm is 99 per cent protected from the effect of a conflict shock. $R_{m}=0.01$ (or $1-R_{m}=0.99$ ) represents zero resilience where the farm has almost no protection from the effect of a conflict shock. This resilience framework can be factored in by expanding Equation 7 as follows:

$\frac{\partial * A_{E t}}{\partial \epsilon}=\left(1-R_{m}\right) \frac{\partial * A_{E t}}{\partial c_{t}} \cdot \frac{\partial c_{t}}{\partial \epsilon}+\left(1-R_{m}\right) \frac{\partial * A_{E t}}{\partial \epsilon}$.

From Equation 8, for a farm that has almost absolute resilience, $R_{m}=1$ and $\left(\partial * A_{E t}\right) / \partial \epsilon=0$, meaning that the farm is totally insulated from the conflict-related shock. On the other hand, for a farm that has zero resilience, $R_{m}=0$, meaning that the farm is not at all insulated from the conflict-related shock and bears the full effect of the shock. Of course, in reality, absolute resilience is elusive so that $\left(\partial * A_{E t}\right) / \partial \epsilon$ is negative for a more resilient farm but less in absolute magnitude, compared to a non-resilient farm. Indicators of resilience found from the literature may be appropriate starting points for the impact of resilience on the adverse effects from climate and conflict shocks. 


\section{EMPIRIGAL FRAMEWORK}

\subsection{Data}

We utilise three main data sources in our empirical analysis: (1) the APRA household survey for data on agricultural variables, (2) ACLED for data on armed conflict incidents, and (3) the Peace Research Institute of Oslo (PRIO) GRID dataset for data on climate related factors. The APRA surveys for Nigeria were conducted in Kaduna and Ogun states. These surveys were aimed at identifying substantial gaps in available evidence on what are the most effective, pro-poor, gender equitable pathways to agricultural commercialisation, reflecting a wider lack of good quality statistics for economic development. These household surveys were conducted at the household level and recorded information on member details, agricultural plot ownership, details of family labour and hired labour, crop details and sales, livestock ownership and sales, income sources and assets, poverty, food security and several gender specific questions. The datasets cover 2,110 households, with 49 per cent of them operating more than 5 ha of land. They cover three local government areas (LGAs) each from both Ogun and Kaduna states, representing both states equally. We filter out households which were always mediumor large-scale farmers, reducing our sample size to 1,204. These include all SHFs $(1,078)$ and the MSFs and LCFs that completed the transition during the last five years (126). Kaduna State has 50 such households whereas Ogun State accounts for 76 households which transitioned from SHFs to larger scales.

Of particular interest in the datasets is the special module on the ability of smallholder farmers to transition to large scales. This module was specifically designed to correct for the under-representation of (MSFs) and LCFs in traditional Living Standards Measurement Study surveys. We construct our main dependent variable using this module. With SHFs defined as farms operating less than 5 ha, the module specifically asks households whether the household completed a transition from SHF to larger scales in the last ten years. They were also asked to report the exact year of the transition. Using this information, we construct our main dependent variable, a household's ability to transition from SHFs to MSFs/LCFs (whether a current MSF or LCF had transitioned from being a $\mathrm{SHF}$ in the last five years). Note that the endogenous dummy variable takes on the value of 1 if a transition occurred and 0 otherwise. This variable is coded as a binary variable to simplify our empirical analysis. Our choice of five years (2014 to 2018) as the threshold is aimed at focusing more on recent land holding transitions. This is a more appropriate time frame than the ten years that our database could possibly provide since the conflict measures we employ cover events occurring from 2009 to 2013. To make any type of causal argument, the relevant conflict must occur before the transition being examined. We were able to construct this variable with a fair amount of accuracy because the specific survey question asked which year the transition was made.

Our main resilience related factors, including education levels (whether the head of the household completed primary education), total asset value (in thousands of Nigerian Naira ( $\$ 1,000)$, off-farm income levels (in $\mathrm{N1}, 000$ ), and total household income (in $\mathrm{N1}, 000$ ), are also extracted from the APRA survey.

With respect to control variables, data on the climaterelated factors are extracted from the PRIO-GRID version 2.0 dataset (Tollefsen, Strand and Buhaug 2012). The drought variable is constructed using the Standardized Precipitation-Evapotranspiration Index (SPEI) (Beguería, Vicente-Serrano and AnguloMartínez 2010). It measures the average proportion of the year the household's grid experienced drought conditions, obtained by dividing the number of days the grid experienced drought by the total number of days in a year. The precipitation variable is defined as the yearly total precipitation (in millimetres) in the grid, based on monthly meteorological statistics (Huffman et al. 2009). The temperature variable is the yearly mean temperature (in degrees Celsius) in the grid, based on monthly meteorological statistics from GHCN/CAMS, developed at the Climate Prediction Centre, NOAA/ National Weather Service (Fan and van den Dool 2008).

We measure conflict intensity using data from ACLED. ACLED is a disaggregated data collection, analysis and crisis mapping project which collects the dates, 
actors, locations, fatalities, and modalities of all reported political violence and protest events across Africa, Asia, the Middle East, Latin America and the Caribbean, Europe and the Balkans (Raleigh et al. 2010). ACLED provides information on political violence and protests, which is disaggregated by date (when the event happened); type of violence (what happened); actors (who is involved); and location (where the event happened). Reports of violence are broken down into individual, discrete events, determined by whether they took place at a different time, involved different types of violence or actors, or occurred in different locations. Our main shock variable is the household's exposure to conflict, which is measured by the total number of conflict related fatalities that took place within a predefined buffer zone (20km radius) around each household. The mean counts for conflict incidents and casualties within $20 \mathrm{~km}$ from the farm are 11.75 and 45.45 , respectively. Table 4.1 presents the summary statistics for our data.

\subsection{Empirical model}

We use a logit model to estimate the effect of resilience factors in mitigating the negative impacts of conflicts on the transition from SHFs to larger scales. The model

$\Omega_{i}=\frac{e^{K_{i}^{\prime} \beta}}{1+e^{K_{i}^{\prime} \beta}}$

where $\Omega_{i}$ represents the probability of transition from SHFs to larger scales for household $i$. $K_{i}$ represents the vector of all independent variables, including each household's exposure to armed conflicts and various resilience related factors. The resilience related factors are linked with the conflict intensity measure to examine whether such factors mitigate the negative impacts of conflict. We implement the logit regressions by first pooling the data from both Ogun and Kaduna states and then treating both states separately. All regressions are estimated using standard errors clustered at the LGA level.

Table 4.1: Summary of statistics

\begin{tabular}{|l|l|l|l|l|l|}
\hline & $\begin{array}{l}\text { Number of } \\
\text { households }\end{array}$ & Mean & $\begin{array}{l}\text { Standard } \\
\text { deviation }\end{array}$ & Minimum & Maximum \\
\hline Transition & 1,204 & 0.10 & 0.31 & 0 & 1 \\
\hline Fatalities (20km radius) & 1,204 & 39.83 & 104.47 & 0 & 531 \\
\hline Primary school education & 1,204 & 0.14 & 0.34 & 0 & 1 \\
\hline Asset value & 1,204 & 14.38 & 20.27 & 0 & 469.15 \\
\hline Net off-farm income & 1,204 & 230.42 & 471.00 & -85 & 9958 \\
\hline Hereditary land (ha) & 1,204 & 10.00 & 115.73 & 0 & 2015 \\
\hline Migration (1/0) & 1,204 & 0.15 & 0.36 & 0 & 1 \\
\hline Drought & 1,204 & 0.08 & 0.01 & 0 & 0.08333 \\
\hline Precipitation & 1,204 & 1546.27 & 259.47 & 931.981 & 1796.74 \\
\hline Temperature & 1,204 & 27.30 & 1.18 & 25.25 & 29.085 \\
\hline Social safety nets & 1,204 & 0.32 & 0.47 & 0 & 1 \\
\hline
\end{tabular}

Source: Authors' own 


\section{EMPIRIGAL RESULTS}

\subsection{Role of resilience factors in mitigating the impacts of conflict on the transition}

Tables 5.1-5.4 present our results for the effects of specific resilience factors in moderating the impacts of armed conflicts on the transition of SHFs to larger scales. Tables 5.1 and 5.2 present our pooled results for both Kaduna and Ogun states, whereas Tables 5.3 and 5.4 report result for both states separately.

In Table 5.1, we measure the effect of only two resilience factors, asset value and net off-farm income,

Table 5.1: Role of resilience factors in mitigating the negative impacts of conflict on the transition to larger scales (asset value and net off-farm income as resilience factors - pooled data)

\begin{tabular}{|c|c|c|c|c|}
\hline \multicolumn{4}{|c|}{ Dependent variable: probability of transition to larger scales } & \multirow[b]{2}{*}{ (4) } \\
\hline & (1) & (2) & (3) & \\
\hline & (without controls) & (with controls) & (without controls) & (with controls) \\
\hline \multirow[t]{2}{*}{ Fatalities (20km radius) } & $-0.004^{\star \star}$ & $-0.005^{\star \star}$ & -0.001 & -0.001 \\
\hline & $(-2.50)$ & $(-2.06)$ & $(-1.08)$ & $(-0.57)$ \\
\hline \multirow[t]{2}{*}{ Asset value } & 0.010 & 0.008 & & 0.010 \\
\hline & $(0.86)$ & $(0.71)$ & & $(0.72)$ \\
\hline \multirow[t]{2}{*}{ Net off-farm income } & & $0.001^{\star \star \star}$ & $0.001^{* \star \star}$ & $0.001^{\star \star \star}$ \\
\hline & & $(3.37)$ & $(8.24)$ & $(3.76)$ \\
\hline \multirow[t]{2}{*}{ fatal20 * asset value } & $0.000^{\star \star}$ & $0.000^{*}$ & & \\
\hline & (2.03) & $(1.92)$ & & \\
\hline \multirow[t]{2}{*}{ fatal20 * net off-farm income } & & & $-0.000^{\star \star \star}$ & $-0.000^{\star \star \star}$ \\
\hline & & & $(-2.78)$ & $(-2.63)$ \\
\hline \multirow[t]{2}{*}{ Hereditary land (ha) } & & $-0.001^{\star \star \star}$ & & $-0.001^{\star \star \star}$ \\
\hline & & $(-3.26)$ & & $(-3.31)$ \\
\hline \multirow[t]{2}{*}{ Migration (1/0) } & & $0.983^{\star \star \star}$ & & $1.009^{\star \star \star}$ \\
\hline & & (3.33) & & $(3.66)$ \\
\hline \multirow[t]{2}{*}{ Drought (SPEI) } & & $-16.891^{\star \star \star}$ & & $-16.989^{\star \star \star}$ \\
\hline & & $(-5.04)$ & & $(-4.98)$ \\
\hline \multirow[t]{2}{*}{ Precipitation (in mm) } & & 0.000 & & 0.000 \\
\hline & & $(0.30)$ & & $(0.28)$ \\
\hline \multirow[t]{2}{*}{ Temperature $\left({ }^{\circ} \mathrm{C}\right)$} & & 0.100 & & 0.092 \\
\hline & & $(0.97)$ & & $(0.94)$ \\
\hline \multirow[t]{2}{*}{ Constant } & $-2.264^{\star \star \star}$ & $-4.248^{*}$ & $-2.359^{\star \star \star}$ & $-4.088^{\star \star}$ \\
\hline & $(-13.36)$ & $(-1.93)$ & $(-22.02)$ & $(-1.97)$ \\
\hline$N$ & 1204 & 1204 & 1204 & 1204 \\
\hline$R^{2}$ & 0.0182 & 0.0758 & 0.0326 & 0.0766 \\
\hline
\end{tabular}

Source: Authors' own

Notes: t-statistics are in parenthesis and ${ }^{*} \mathrm{p}<0.10 ; * * \mathrm{p}<0.5 ; * * \mathrm{p}<0.01$. Both asset value and off-farm income are measured in Naira. 
in influencing the transition of SHFs to larger scales. These resilience factors moderate the impacts of exposure to armed conflicts on the transition variable, captured by the interaction term. In models 1 and 2, as expected, the conflict intensity variable, measured by the number of fatalities occurring in a household's $20 \mathrm{~km}$ neighbourhood, negatively impacts on the probability of transition at 5 per cent levels $(-0.004$ for the model without controls and -0.005 for the model with controls). These are quite similar. That is, in Kaduna and Ogun states, conflicts occurring within $20 \mathrm{~km}$ retard the probability of a larger farm having transitioned from SHF. Regarding resilience factors, an increase in asset value does not significantly affect the transition to larger scales, hinting at the possibility that currently large asset holdings, by themselves, do not have the direct impact of facilitating the scale-up of smallholder farmers. However, the moderating effects of asset holdings as a resilience factor is well captured by the significant and positive coefficient for its interaction term with conflict

Table 5.2: Role of resilience factors in mitigating the negative impacts of conflict on the transition to larger scales (household income and education as resilience factors - pooled data)

\begin{tabular}{|c|c|c|c|c|}
\hline \multicolumn{5}{|c|}{ Dependent variable: probability of transition to larger scales } \\
\hline & $(1)$ & (2) & (3) & (4) \\
\hline & $\begin{array}{l}\text { (without } \\
\text { controls) }\end{array}$ & (with controls) & $\begin{array}{l}\text { (without } \\
\text { controls) }\end{array}$ & (with controls) \\
\hline \multirow[t]{2}{*}{ Fatalities (20km radius) } & $-0.004^{\star \star \star}$ & $-0.005^{\star \star \star}$ & $-0.004^{\star \star \star}$ & $-0.006^{\star \star \star}$ \\
\hline & $(-4.26)$ & $(-3.33)$ & $(-4.13)$ & $(-4.92)$ \\
\hline \multirow[t]{2}{*}{ Primary school education } & $1.164^{\star \star \star}$ & $0.956^{\star \star \star}$ & & $1.028^{\star \star \star}$ \\
\hline & $(5.83)$ & $(3.23)$ & & $(3.70)$ \\
\hline \multirow[t]{2}{*}{ Access to safety nets } & & & $0.487^{\star \star}$ & 0.351 \\
\hline & & & $(2.22)$ & $(1.35)$ \\
\hline \multirow[t]{2}{*}{ fatal20 * primary school education } & $0.002^{\star \star}$ & $0.003^{\star \star \star}$ & & \\
\hline & $(2.29)$ & $(2.64)$ & & \\
\hline \multirow[t]{2}{*}{ fatal20 * access to safety nets } & & & $0.005^{\star \star \star}$ & $0.006^{\star \star \star}$ \\
\hline & & & (7.33) & (8.98) \\
\hline \multirow[t]{2}{*}{ Asset value } & & 0.009 & & 0.009 \\
\hline & & $(0.73)$ & & $(0.75)$ \\
\hline \multirow[t]{2}{*}{ Net off-farm income } & & $0.001^{* * *}$ & & $0.001^{\star \star \star}$ \\
\hline & & $(3.08)$ & & $(3.51)$ \\
\hline \multirow[t]{2}{*}{ Hereditary land (ha) } & & $-0.001^{\star \star \star}$ & & $-0.001^{\star \star}$ \\
\hline & & $(-2.70)$ & & $(-2.12)$ \\
\hline \multirow[t]{2}{*}{ Migration } & & $0.966^{\star \star \star}$ & & $0.971^{\star \star \star}$ \\
\hline & & (3.39) & & $(3.44)$ \\
\hline \multirow[t]{2}{*}{ Drought (SPEI) } & & $-16.886^{\star \star \star}$ & & $-16.302^{\star \star \star}$ \\
\hline & & $(-4.57)$ & & $(-5.35)$ \\
\hline \multirow[t]{2}{*}{ Precipitation (in $\mathrm{mm}$ ) } & & -0.000 & & -0.000 \\
\hline & & $(-0.15)$ & & $(-0.41)$ \\
\hline \multirow[t]{2}{*}{ Temperature $\left({ }^{\circ} \mathrm{C}\right)$} & & 0.118 & & 0.062 \\
\hline & & $(1.12)$ & & $(0.68)$ \\
\hline \multirow[t]{2}{*}{ Constant } & $-2.280^{\star \star \star}$ & $-4.555^{\star \star}$ & $-2.274^{\star \star \star}$ & -2.988 \\
\hline & $(-20.20)$ & $(-2.05)$ & $(-13.85)$ & $(-1.49)$ \\
\hline$N$ & 1204 & 1204 & 1204 & 1204 \\
\hline$R^{2}$ & 0.0369 & 0.0979 & 0.0217 & 0.110 \\
\hline
\end{tabular}

Source: Authors' own

Notes: t-statistics are in parenthesis and $* \mathrm{p}<0.10 ; * * \mathrm{p}<0.5 ; * * * \mathrm{p}<0.01$. Both asset value and off-farm income are measured in Naira. Primary school education, access to safety nets and migration are binary variables. 
intensity. Based on these coefficients, we conclude that households with high asset value can cushion the negative impacts of conflict on their ability to scale-up, to a reasonable degree.

In Table 5.1 (models 3 and 4), we replicate the results in models 1 and 2, but with net off-farm income replacing the asset value variable as the resilience factor. The interaction term between the off-farm income variable and conflict intensity has a significant and negative coefficient, meaning that off-farm income is not a resilience building factor for households who are trying to scale-up their agricultural operations. If households with significant off-farm income sources consider agriculture to be risky in the onset of conflict, they might scale down their farming operations, concentrate on their off-farm activities and spend their money elsewhere. Previous literature also points to the fact that physical endowments such as land could be a liability for households trying to flee from active conflict zones (Pivovarova and Swee 2015).

In Table 5.1, the results generally suggest that households who migrated from other places are more likely to undergo transition from SHF to larger scales. This suggests that in-migrants, perhaps displaced from conflict zones, are more likely to scale-up. The growth of new farms owned by IDPs is noticeable in places where they migrate, including and especially Kaduna State. Even in Ogun State, new farmers migrating from Lagos State are very likely to have deliberately chosen farming as a new occupation, moved to Ogun State as more progressive farmers, leverage their connections to opportunities in the Lagos metropolitan markets, and be more apt to expand their land base.

To the contrary, the amount of land inherited does not facilitate the transition to larger scales, perhaps suggesting that inheritance may be a burden which reduces the motivation to grow. In addition, inheritance could reduce the constraint faced by a farmer by providing him/her with land that would have had to be purchased in the absence of an inheritance. As expected, the drought variable, measured by the proportion of year that the grid that the household belongs to experienced drought, shows a statistically significant and negative association with the probability of a farm transitioning to a larger scale. The temperature and precipitation variables do not have a significant impact on the transition from SHF to larger scales.

Regarding the roles of resilience factors, Table 5.2 results are more interesting. In Table 5.2, we use the primary school education completion status of the household head and household's access to safety nets as resilience related factors. We use primary school education completion as the resilience factor rather than a higher benchmark such as secondary education since the average household head in our sample has not completed primary education. As expected, in models 1 through 4, conflict intensity negatively impacts on a SHF's ability to scale up. The impact remains significant with or without the addition of the controls. However, household heads who completed primary education increases the transition probability for their respective household. Access to safety nets also increases the likelihood of transition from SHFs to larger scales. The roles of resilience factors in mitigating the effects of conflict are captured by the interaction terms. Interaction terms for both primary school education and safety net access variables display significant and positive coefficients, suggesting that both these variables play a significant role in mitigating the negative impacts of armed conflicts on scale expansion. These findings are consistent with the previous findings of Frankenberger and Smith (2015) and d'Errico and Di Giuseppe (2018), which suggest that adaptive capacity (measured by education outcome here) and access to social safety nets are critical in defining resilience. Other control variables show similar results as that of Table 5.1.

\subsection{Differential effects of resilience factors: Kaduna versus Ogun states}

In Tables 5.3 and 5.4, we report results for regressions where we treat Kaduna and Ogun states separately. In Table 5.3, for both states, as expected, exposure to conflict negatively impacts on the transition probability. However, as seen in model 1, while the coefficient of asset value by itself is not statistically significant, that of its cross term with the conflict variable is positive and significant. This suggests the important role of asset value, a resilience factor, in mitigating the negative impacts of conflict in Kaduna State. This mitigation effect is more pronounced for Kaduna State than for Ogun State. These results suggest that in Ogun State, resilience contributes to the scale-up of smallholder farmers through farmers having greater assets. However, in Kaduna State, while resilience does not directly contribute to scale-up capacity, it mitigates the adverse effect of conflict. This is not surprising, given the fact that Kaduna State has been relatively more prone to armed conflict incidents when compared with Ogun State. Since the intensity of conflicts is higher in Kaduna State, the mitigating impacts of resilience factors are also significantly higher. Moreover, relatively low conflict intensity levels, as is the case in Ogun, may not require households to deploy more permanent resilience factors such as assets for farm scale-up. On 
the other hand, for both states, off-farm income does not play a crucial role in the amelioration of conflict impacts, as indicated by the insignificant coefficient values of its interaction terms.

Next, we discuss the relative differences in the effects of other control variables in the transition probability. Again, the acquisition of land through inheritance seems to have a negative impact on the likelihood of transition. However, recent migration significantly increases the probability of transitioning in Ogun State, but not in Kaduna State. Again, this is possibly due to the Lagos metropolitan exposure of Ogun State farmers. Furthermore, anecdotal evidence suggests that several new farmers and young entrepreneurs in Lagos view Ogun State as an attractive destination for agricultural expansion, primarily owing to the land incentives offered by the Ogun State Government. In addition, many of the new migrants to Kaduna State are likely to be IDPs with very little initial endowments to start big agricultural operations or scale-up. In both states, the intensity of droughts negatively impacts the probability of transitioning to a larger scale. More precipitation means greater probability of transitioning in Kaduna State, but not in Ogun. This is probably because Kaduna State has experienced more intense drought conditions, making the marginal effects of precipitation much greater in Kaduna, vis-à-vis Ogun State.

In Table 5.4, we report results for the effects of primary school education and safety net access as resilience factors for Kaduna and Ogun states separately. In all four models, exposure to conflict intensity negatively impacts on the probability of transition from SHFs

Table 5.3: Role of resilience factors in mitigating the negative impacts of conflict on transition to larger scales (asset value and net off-farm income as resilience factors)

\begin{tabular}{|c|c|c|c|c|}
\hline \multicolumn{5}{|c|}{ Dependent variable: probability of transition to larger scales } \\
\hline & (1) & (2) & $(3)$ & $(4)$ \\
\hline & \multicolumn{2}{|c|}{ Kaduna State } & \multicolumn{2}{|l|}{ Ogun State } \\
\hline \multirow[t]{2}{*}{ Fatalities (20km radius) } & $-0.002^{\star \star \star}$ & 0.000 & -0.013 & $-0.032^{\star \star \star}$ \\
\hline & $(-6.15)$ & $(0.07)$ & $(-0.57)$ & $(-2.89)$ \\
\hline \multirow[t]{2}{*}{ Asset value } & 0.000 & & $0.058^{\star \star \star}$ & \\
\hline & $(0.09)$ & & $(5.86)$ & \\
\hline \multirow[t]{2}{*}{ Net off-farm income } & & $0.001^{* * *}$ & & 0.000 \\
\hline & & $(3.04)$ & & $(0.86)$ \\
\hline \multirow[t]{2}{*}{ fatal20 * asset value } & $0.000^{\star \star \star}$ & & -0.001 & \\
\hline & $(47.08)$ & & $(-0.90)$ & \\
\hline \multirow[t]{2}{*}{ fatal20 * net off-farm income } & & $-0.000^{\star \star \star}$ & & $0.000^{*}$ \\
\hline & & $(-4.75)$ & & (1.73) \\
\hline \multirow[t]{2}{*}{ Hereditary land (ha) } & $-0.001^{\star \star \star}$ & $-0.001^{\star \star \star}$ & $-0.001^{* *}$ & -0.001 \\
\hline & $(-19.81)$ & $(-19.80)$ & $(-2.33)$ & $(-1.60)$ \\
\hline \multirow[t]{2}{*}{ Migration (1/0) } & 0.112 & 0.230 & $1.544^{\star \star \star}$ & $1.451^{\star \star \star}$ \\
\hline & $(0.28)$ & $(0.60)$ & (7.99) & (6.88) \\
\hline \multirow[t]{2}{*}{ Drought (SPEI) } & $-7.103^{\star \star \star}$ & $-8.862^{\star \star \star}$ & $-19.322^{\star \star \star}$ & $-18.781^{\star \star \star}$ \\
\hline & $(-12.52)$ & $(-28.36)$ & $(-8.10)$ & $(-7.81)$ \\
\hline \multirow[t]{2}{*}{ Precipitation (in $\mathrm{mm}$ ) } & $0.003^{\star \star \star}$ & $0.003^{* \star *}$ & 0.000 & 0.000 \\
\hline & $(11.35)$ & $(5.94)$ & (.) & (.) \\
\hline \multirow[t]{2}{*}{ Temperature $\left({ }^{\circ} \mathrm{C}\right)$} & $0.056^{* *}$ & 0.002 & $4.062^{\star \star \star}$ & $4.335^{\star \star \star}$ \\
\hline & $(2.34)$ & $(0.04)$ & $(5.96)$ & (8.64) \\
\hline \multirow[t]{2}{*}{ Constant } & $-7.253^{\star \star \star}$ & $-5.188^{\star \star \star}$ & $-116.594^{\star \star \star}$ & $-123.599^{\star \star \star}$ \\
\hline & $(-8.64)$ & $(-2.69)$ & $(-6.04)$ & $(-8.70)$ \\
\hline$N$ & 583 & 583 & 621 & 621 \\
\hline$R^{2}$ & 0.0209 & 0.0292 & 0.163 & 0.127 \\
\hline
\end{tabular}

Source: Authors' own

Notes: t-statistics are in parenthesis and ${ }^{*} \mathrm{p}<0.10 ; * * \mathrm{p}<0.5 ; * * * \mathrm{p}<0.01$. Both asset value and off-farm income are measured in Naira. 
to larger scales. As a resilience factor, across both states, primary school educated household heads increase the likelihood of transition. Its mitigation role as a resilience factor is worth noting. In both states, access to education mitigates the negative impacts of armed conflicts on the transition variable. On the other hand, access to safety nets play a significant role as a mitigator to the effect of conflict on land expansion only for Kaduna State.

Table 5.4: Role of resilience in mitigating the negative impacts of conflict on the transition to larger scales (household income and education as resilience factors)

\begin{tabular}{|c|c|c|c|c|}
\hline \multicolumn{5}{|c|}{ Dependent variable: probability of transition to larger scales } \\
\hline & $(1)$ & (2) & $(3)$ & $(4)$ \\
\hline & \multicolumn{2}{|c|}{ Kaduna State } & \multicolumn{2}{|l|}{ Ogun State } \\
\hline \multirow[t]{2}{*}{ Fatalities (20km radius) } & $-0.004^{\star \star \star}$ & $-0.006^{\star \star \star}$ & $-0.021^{\star \star}$ & $-0.035^{\star \star}$ \\
\hline & $(-3.70)$ & $(-3.97)$ & $(-2.00)$ & $(-2.13)$ \\
\hline \multirow[t]{2}{*}{ Primary school education } & $1.423^{\star \star \star}$ & $1.490^{\star \star \star}$ & $0.975^{\star \star \star}$ & $0.551^{\star \star}$ \\
\hline & $(4.22)$ & $(4.55)$ & $(9.56)$ & $(2.13)$ \\
\hline \multirow[t]{2}{*}{ Access to safety nets } & & -0.341 & & 0.546 \\
\hline & & $(-0.77)$ & & $(1.60)$ \\
\hline \multirow[t]{2}{*}{ fatal 20 * primary school education } & $0.002^{\star \star \star}$ & & $-0.031^{\star \star \star}$ & \\
\hline & $(4.95)$ & & $(-8.05)$ & \\
\hline \multirow[t]{2}{*}{ fatal20 * access to safety nets } & & $0.007^{\star \star \star}$ & & 0.011 \\
\hline & & $(6.77)$ & & $(0.94)$ \\
\hline \multirow[t]{2}{*}{ Asset value } & 0.001 & 0.001 & $0.046^{\star \star \star}$ & $0.044^{\star \star \star}$ \\
\hline & $(0.32)$ & $(0.26)$ & $(11.86)$ & $(10.84)$ \\
\hline \multirow[t]{2}{*}{ Net off-farm income } & 0.001 & 0.001 & $0.001^{\star \star}$ & $0.001^{\star \star \star}$ \\
\hline & $(1.11)$ & $(1.50)$ & $(2.57)$ & $(3.07)$ \\
\hline \multirow[t]{2}{*}{ Hereditary land (ha) } & $-0.001^{* \star *}$ & $-0.001^{\star \star \star}$ & $-0.001^{*}$ & -0.000 \\
\hline & $(-27.08)$ & $(-18.85)$ & $(-1.79)$ & $(-1.10)$ \\
\hline \multirow[t]{2}{*}{ Migration (1/0) } & 0.176 & 0.225 & $1.507^{\star \star \star}$ & $1.569^{\star \star \star}$ \\
\hline & $(0.51)$ & $(0.67)$ & (7.83) & $(8.27)$ \\
\hline \multirow[t]{2}{*}{ Drought (SPEI) } & $-7.625^{\star \star \star}$ & $-7.617^{\star \star \star}$ & $-22.242^{\star \star \star}$ & $-19.649^{\star \star \star}$ \\
\hline & $(-11.02)$ & $(-14.08)$ & $(-9.68)$ & $(-9.87)$ \\
\hline \multirow[t]{2}{*}{ Precipitation (in mm) } & $0.003^{\star \star \star}$ & $0.003^{\star \star \star}$ & 0.000 & 0.000 \\
\hline & $(9.32)$ & $(6.22)$ & (.) & (.) \\
\hline \multirow[t]{2}{*}{ Temperature $\left({ }^{\circ} \mathrm{C}\right)$} & $0.066^{\star \star}$ & 0.043 & $4.631^{\star \star \star}$ & $4.312^{\star \star \star}$ \\
\hline & $(2.20)$ & $(1.08)$ & $(18.18)$ & $(16.22)$ \\
\hline \multirow[t]{2}{*}{ Constant } & $-7.332^{\star \star \star}$ & $-7.185^{\star \star \star}$ & $-132.644^{\star \star \star}$ & $-123.972^{\star * \star}$ \\
\hline & $(-13.06)$ & $(-6.14)$ & $(-18.27)$ & $(-15.77)$ \\
\hline$N$ & 583 & 583 & 621 & 621 \\
\hline$R^{2}$ & 0.0728 & 0.0918 & 0.193 & 0.201 \\
\hline
\end{tabular}

Source: Authors' own

Notes: t-statistics are in parenthesis and ${ }^{*} \mathrm{p}<0.10 ;{ }^{* *} \mathrm{p}<0.5 ; * * * \mathrm{p}<0.01$. Both asset value and off-farm income are measured in Naira. Primary school education, access to safety nets and migration are binary variables. 


\section{CONCLUSIONS AND POLICY RECOMMENDATIONS}

Resilience building is emerging as an important factor in mitigating the effects of shocks. Considering the growing incidence of conflict in parts of Africa, its implications for agricultural development in conflict settings are noteworthy. There was an evident absence of empirical evidence on the role of resilience in mitigating the adverse impacts of conflicts on smallholder farmers' ability to scale-up. Our application of the concept of resilience to farms in locations that are not directly in war or major conflict zones plugs an important gap in the literature.

Our key question in this paper is "do resilience factors help mitigate the negative impacts of conflict shocks on land expansion in areas not directly within an active war zone?" Based on the results of this study, our answer is yes. With respect to the role of resilience factors, we find that (1) the attainment of primary education by the household head contributes positively to scale expansion directly, but also indirectly helps mitigate the negative effects of conflict; (2) that access to safety nets contributes positively to scale expansion directly, but also indirectly helps mitigate the negative effects of conflict on scale expansion; but (3) that while off-farm income contributes to scale expansion directly, it does not help in mitigating the adverse effects of conflict on the ability to scale up for smallholder farmers. The magnitude of the effects is also sizeable. For instance, an additional fatality in the neighbouring $20 \mathrm{~km}$ radius of a SHF hinders the probability of its scaling up by 0.004. Given that the average number of fatalities in our sample is about 40 , for an average SHF, exposure to conflicts reduces the probability of transition by 0.16. Similarly, having completed primary education mitigates the negative effects of the conflict by about 50 per cent.

We also find that the mitigating roles of resilience factors are more pronounced in Kaduna State than in Ogun State. This is expected, considering the greater exposure of Kaduna State to more debilitating forms of conflict. Since both states are not in active war zones, our results suggest that resilience building can be a tool for mitigating the adverse effects of conflict shocks even in areas that are not facing active conflicts. In such areas, we suggest that policy makers consider resilience building as a mechanism for cushioning the impacts of conflict shocks, including in areas slated to increase their participation in larger-scale enterprises requiring more land than smallholder farmers' current farm.

The resilience building tools implied by this study as being relevant are improved education, improved access to safety nets and improved assets. Better formal education for existing farmers may not be feasible but educated individuals can be encouraged to farm or be lured into farming. If the aforementioned formers can be more resilient, they are thus able to better withstand the impacts of conflict shocks. Improved safety nets can be achieved both through government programmes to help farmers and better extension education to highlight the importance of developing such safety nets. While large asset holdings can be viewed by some as a distraction in volatile conflict settings, its beneficial effect as a resilience factor makes it desirable in areas affected by conflict. As resilience building is relevant in conflict mitigation, we urge closer attention to it in policy making in conflict and conflict-affected regions. 
Aall, P. and Crocker, C.A. (2019) 'Building Resilience and Social Cohesion in Conflict', Global Policy 10(S2): 68-75

ACLED (2019) Armed Conflict Location \& Event Data Project (ACLED), https://www.acleddata.com (accessed 15 August 15 2020)

Adelaja, A. and George, J. (2019a) 'Effects of Conflict on Agriculture: Evidence from the Boko Haram Insurgency', World Development 117: 184-195

Adelaja, A. and George, J. (2019b) 'Terrorism and Land Use in Agriculture: The Case of Boko Haram in Nigeria', Land Use Policy 88: 104116

Adger, W.N. (2000) 'Social and Ecological Resilience: Are They Related?', Progress in Human Geography 24(3): 347-364

Adger, W.N. et al. (2009) 'Are There Social Limits to Adaptation to Climate Change?', Climatic Change 93: 335354

Akresh, R.; Lucchetti, L. and Thirumurthy, H. (2012) 'Wars and Child Health: Evidence from the Eritrean-Ethiopian Conflict', Journal of Development Economics 99(2): 330-340

Alinovi, L. and Romano, D. (2010) Livelihoods Strategies and Household Resilience to Food Insecurity: An Empirical Analysis to Kenya, European Report on Development, Rome: Food and Agriculture Organization of the United Nations

Arias, M.A.; Ibáñez, A.M. and Zambrano, A. (2019) 'Agricultural Production Amid Conflict: Separating the Effects of Conflict into Shocks and Uncertainty', World Development 119: 165-184

Barrett, C. (2008) 'Smallholder Market Participation: Concepts and Evidence from Eastern and Southern Africa', Food Policy 33(4): 299-317

Barrett, C.B. and Constas, M.A. (2014) 'Toward a Theory of Resilience for International Development Applications', Proceedings of the National Academy of Sciences of the United States of America, National Academy of Sciences, 111(40): 14625-14630

Barrett, C.B.; Reardon, T. and Webb, P. (2001) 'Nonfarm Income Diversification and Household Livelihood Strategies in Rural Africa: Concepts, Dynamics, and Policy Implications', Food Policy 26(4): 315-331

Beguería, S.: Vicente-Serrano, S.M. and Angulo-Martínez, M. (2010) 'A Multiscalar Global Drought Dataset: The SPEI Base: A New Gridded Product for the Analysis of Drought Variability and Impacts', Bulletin of the American Meteorological Society 91(10): 1351-1356

BIFAD (2019) Agriculture and Food Security in Fragile and Conflict-Affected Contexts, Washington DC: United States Agency for International Development

Bozzoli, C. and Brück, T. (2009) 'Agriculture, Poverty, and Postwar Reconstruction: Micro-Level Evidence from Northern Mozambique', Journal of Peace Research 46(3): 377-397 
Breisinger, C. et al. (2014) How to Build Resilience to Conflict: The Role of Food Security, Washington, DC: International Food Policy Research Institute

Bundervoet, T.: Verwimp, P. and Akresh, R. (2009) 'Health and Civil War in Rural Burundi', Journal of Human Resources. 44(2): 536-563

Carr, E.R. (2019) 'Properties and Projects: Reconciling Resilience and Transformation for Adaptation and Development', World Development 122: 70-84

Choularton, R.; Frankenberger, T., Kurtz J. and Nelson, S. (2015) Measuring Shocks and Stressors as Part of Resilience Measurement, Resilience Measurement Technical Working Group, Technical Series No.5, Rome: Food and Agriculture Organization of the United Nations

Cissé, J.D. and Barrett, C.B. (2018) 'Estimating Development Resilience: A Conditional Moments-based Approach', Journal of Development Economics 135: 272-284

d'Errico, M. and Di Giuseppe, S. (2018) 'Resilience Mobility in Uganda: A Dynamic Analysis', World Development 104: 78-96

D'Souza, A. and Jolliffe, D. (2013) ‘Conflict, Food Price Shocks, and Food Insecurity: The Experience of Afghan Households', Food Policy 42: 32-47

Eklund, L; Degerald, M., Brandt, M., Prishchepov, A.V. and Pilesjö, P. (2017) 'How Conflict Affects Land Use: Agricultural Activity in Areas Seized by the Islamic State', Environmental Research Letters 12(5): 054004

Fan, Y. and van den Dool, H. (2008) 'A Global Monthly Land Surface Air Temperature Analysis for 1948-Present', Journal of Geophysical Research 113(D1): D01103

FAO (2016) RIMA-Il: Moving Forward the Development of the Resilience Index Measurement and Analysis Model, Rome: Food and Agriculture Organization of the United Nations

FAO, IFAD, UNICEF, WFP and WHO (2017) The State of Food Security and Nutrition in the World 2017. Building Resilience For Peace and Food Security, Rome: Food and Agriculture Organization of the United Nations

Frankenberger, T.R. and Smith, L.C. (2015) Ethiopia Pastoralist Areas Resilience Improvement and Market Expansion (PRIME) Project Impact Evaluation Report of the Interim Monitoring, Feed the Future FEEDBACK, Westat: Rockville, MD

George, J.; Adelaja, A. and Awokuse, T.O. (2020) 'The Agricultural Impacts of Armed Conflicts: The Case of Fulani Militia', European Review of Agricultural Economics, https://doi.org/10.1093/erae/jbaa022 (accessed 25 September 2020)

George, J.; Adelaja, A. and Weatherspoon, D. (2020) 'Armed Conflicts and Food Insecurity: Evidence from Boko Haram's Attacks', American Journal of Agricultural Economics 102(1): 114-131

Gunderson, L.H. (2000) 'Ecological Resilience - In Theory and Application', Annual Review of Ecology and Systematics 31(1): 425-439

Van der Haar, G. and van Leeuwen, M. (2019) 'War-Induced Displacement: Hard Choices in Land Governance', Land 8(6): 88

Hall, B.J.; Tol, W.A., Jordans, M.J.D., Bass, J. and Jong, J.T.V.M. (2014) 'Understanding Resilience in Armed Conflict: Social Resources and Mental Health of Children in Burundi', Social Science and Medicine 114: 121-128 
Hazell, P. (2018) 'Urbanization, Agriculture and Smallholder Farming', in R. Serraj and P. Pingali (eds.) Agriculture and Food Systems to 2050: Global Trend, Challenges and Opportunities, World Scientific: 137-160

Headey, D.D. (2016) 'The Evolution of Global Farming Land: Facts and Interpretations', Agricultural Economics 47(S1): 185-196

Herrero, M. et al. (2017) 'Farming and the Geography of Nutrient Production for Human Use: A Transdisciplinary Analysis', The Lancet Planetary Health 1(1): e33-e42

Holleman, C.; Jackson, J., Sánchez, M.V. and Vos, R. (2017) Sowing the Seeds of Peace for Food Security: Disentangling the Nexus Between Conflict, Food Security and Peace, FAO Agricultural Development Economics Technical Study, Rome: Food and Agriculture Organization of the United Nations

Holling, C.S. (1973) 'Resilience and Stability of Ecological Systems', Annual Review of Ecology and Systematics 4(1): $1-23$

Huffman, G.J.; Adler, R.F., Bolvin, D.T. and Gu, G. (2009) 'Improving the Global Precipitation Record: GPCP Version 2.1', Geophysical Research Letters 36(17): 17808

Jaafar, H.H. and Woertz, E. (2016) 'Agriculture as a Funding Source of ISIS: A GIS and Remote Sensing Analysis', Food Policy 64: 14-25

Jayne, T.S.; Chamberlin, J. and Headey, D.D. (2014) 'Land Pressures, The Evolution of Farming Systems, and Development Strategies in Africa: A Synthesis', Food Policy, 48: 1-17

Jayne, T.S. et al. (2019) 'Are Medium-scale Farms Driving Agricultural Transformation in Sub-Saharan Africa?', Agricultural Economics 50(S1): 75-95

Jones, L. and Tanner, T. (2017) "Subjective Resilience”: Using Perceptions to Quantify Household Resilience to Climate Extremes and Disasters', Regional Environmental Change 17(1): 229-243

Kondylis, F. (2010) 'Conflict Displacement and Labor Market Outcomes in Post-war Bosnia and Herzegovina', Journal of Development Economics 93(2): 235-248

Lowder, S.K., Skoet, J. and Raney, T. (2016) 'The Number, Size, and Distribution of Farms, Smallholder Farms, and Family Farms Worldwide', World Development 87: 16-29

Massad, S.; Stryker, R., Mansour, S. and Khammash, U. (2018) 'Rethinking Resilience for Children and Youth in Conflict Zones: The Case of Palestine', Research in Human Development 5(3-4): 280-293

Masters, W.A. et al. (2013) 'Urbanization and Farm Size in Asia and Africa: Implications for Food Security and Agricultural Research', Global Food Security 2(3): 156-165

Minoiu, C. and Shemyakina, O.N. (2014) 'Armed Conflict, Household Victimization, and Child Health in Côte d'Ivoire', Journal of Development Economics 108: 237-255

Pivovarova, M. and Swee, E.L. (2015) 'Quantifying the Microeconomic Effects of War Using Panel Data: Evidence From Nepal', World Development 66: 308-321

Raleigh, C.; Linke, A., Hegre, H. and Karlson, J. (2010) 'Introducing ACLED: An Armed Conflict Location and Event Dataset', Journal of Peace Research. 47(5): 651-660

Smith, L.C. and Frankenberger, T.R. (2018) 'Does Resilience Capacity Reduce the Negative Impact of Shocks on Household Food Security? Evidence from the 2014 Floods in Northern Bangladesh', World Development 102: 358-376 
Tollefsen, A.F.; Strand, H. and Buhaug, H. (2012) 'PRIO-GRID: A Unified Spatial Data Structure', Journal of Peace Research 49(2): 363-374

Toole, S.; Klocker, N. and Head, L. (2016) 'Re-thinking Climate Change Adaptation and Capacities at the Household Scale', Climatic Change 135(2): 203-209 


\section{ENDNOTES}

'For example, the United States Agency for International Development has highlighted the importance of resilience. Its Bureau of Food Security has recently been renamed the Bureau of Food Security and Resilience.

"The APRA sample covers three LGAs in each of Kaduna and Ogun states. We join the APRA data with data from ACLED and PRIO (see more details about data sources in the empirical section of this report).

iii With respect to land holdings, the exact distinction between SHFs and other larger farms is not consistent. Therefore, the definition of SHFs varies between countries, agro-ecological zones and continents. According to Lowder, Skoet and Raney (2016), SHFs (those holding less than 2ha) represent 84 per cent of farms in the world. In this study, we use less than 5 ha.

iv In comparison, according to (Herrero et al. 2017), MSFs operating between 2 and 20ha produce 50 per cent of total agricultural output while LCFs, operating over 20ha account for 20 per cent.

${ }^{v}$ Idle land is land controlled by the farm household but is neither operated and not under fallow. 
Adelaja, A., et al. (2020) Role of Resilience Factors in Mitigating the Negative Effects of Conflict on Land Expansion, APRA Working Paper 45, Brighton: Future Agricultures Consortium

(c) APRA 2020

ISBN: 978-1-78118-707-4

DOI: 10.19088/APRA.2020.010

\section{(cc) BY-NC-ND}

This is an Open Access report distributed under the terms of the Attribution-Non Commercial-No Derivs 4.0 Unported (CC BY-NC-ND 4.0) Attribution - You must give appropriate credit, provide a link to the license, and indicate if changes were made. You may do so in any reasonable manner, but not in any way that suggests the licensor endorses you or your use. NonCommercial — You may not use the material for commercial purposes. NoDerivatives - If you remix, transform, or build upon the material, you may not distribute the modified material. You are free to: Share - copy and redistribute the material in any medium or format.

https://creativecommons.org/licenses/by-nc-nd/4.0/legalcode

If you use the work, we ask that you reference the APRA website (www.future-agricultures.org/apra/) and send a copy of the work or a link to its use online to the following address for our archive: APRA, Future Agricultures Consortium, University of Sussex, Brighton BN1 9RE, UK (apra@ids.ac.uk)

All APRA Working Papers go through a review process before publication.

\section{Ccreative}

\section{DO YOU HAVE COMMENTS ON THIS PAPER?}

We would welcome your feedback on this working paper!

To provide brief comments, please follow this link to our short APRA Working Paper Feedback form: https://goo.gl/forms/1iVnXhhrlGesfR9

Agricultural Policy Research in Africa (APRA) is a programme of the Future Agricultures Consortium (FAC) which is

generating new evidence and policy-relevant insights on more inclusive pathways to agricultural commercialisation in sub-Saharan Africa. APRA is funded with UK aid from the UK Foreign, Commonwealth \&

Development Office (FCDO) and will run from 2016-2022.

The APRA Directorate is based at the Institute of Development Studies (IDS), UK (www.ids.ac.uk), with regional hubs at the Centre for African Bio-Entrepreneurship (CABE), Kenya, the Institute for Poverty, Land and Agrarian Studies (PLAAS), South Africa, and the University of Ghana, Legon. It builds on more than a decade of research and policy engagement work by the Future Agricultures Consortium (www.future-agricultures.org) and involves more than 100 researchers and communications professionals in Africa, UK, Sweden and USA. 